Research Article

\title{
Failure Mechanisms of Structural Bamboo Using Microstructural Analyses
}

\author{
Mutaz K. Chahrour, ${ }^{1}$ Md. Akter Hosen ID $^{2}$ Yingxin Goh ${ }^{1}{ }^{1},{ }^{1}$ Teong Yen Tong, ${ }^{3}$ \\ Soon Poh Yap $\left(\mathbb{0},{ }^{4}\right.$ and Mohamed Amine Khadimallah $\oplus^{5}$ \\ ${ }^{1}$ Department of Mechanical Engineering, Faculty of Engineering, Universiti Malaya, 50603 Kuala Lumpur, Malaysia \\ ${ }^{2}$ Department of Civil and Environmental Engineering, College of Engineering, Dhofar University, Salalah, Oman \\ ${ }^{3}$ School of Civil Engineering, Engineering Campus, Universiti Sains Malaysia, George Town, 14300 Penang, Malaysia \\ ${ }^{4}$ Department of Civil Engineering, Faculty of Engineering, Universiti Malaya, 50603 Kuala Lumpur, Malaysia \\ ${ }^{5}$ Civil Engineering Department, College of Engineering, Prince Sattam Bin Abdulaziz University, BP 655, \\ Al-Kharj 11942, Saudi Arabia
}

Correspondence should be addressed to Md. Akter Hosen; enggakter@gmail.com and Yingxin Goh; gohyingxin@um.edu.my

Received 24 September 2021; Revised 13 October 2021; Accepted 28 October 2021; Published 20 December 2021

Academic Editor: Abílio De Jesus

Copyright (c) 2021 Mutaz K. Chahrour et al. This is an open access article distributed under the Creative Commons Attribution License, which permits unrestricted use, distribution, and reproduction in any medium, provided the original work is properly cited.

Bamboo is deemed an emerging constructional material with promising application projections due to the reliable natural properties and advantageous structural characteristics. However, there is a lack of systematic studies on the mechanical characteristics of the bamboo species from a microstructural scale. Hence, this paper investigated the primary mechanical properties of the bamboo specimens (Dendrocalamus asper) with further microstructural analysis on the bamboo failure. The direct tensile strength of bamboo specimens was about $226.45 \mathrm{MPa}$, while the final splitting tensile modulus was found to be 2.88 MPa. Microstructural characterisation of the failed tensile specimens indicates that fibre debonding is the main failure mechanism under tensile conditions. On the other hand, splitting and end bearing failure were found on compression test specimens. In addition, nanoindentation tests were carried out on different cell structures to articulate the hardness and Young's modulus. The elastic modulus of the fibre cell walls is three times that of the parenchyma cell walls, yet the hardness values are comparable. This confirms that the specimen failure of previous macromechanical testing is due to crack propagation along the parenchyma cells, instead of the cell walls. Based on the experimental studies discussed in this paper, the conclusion can convey a positive message regarding the ability of bamboo as a primary sustainable substitute for conventional construction materials.

\section{Introduction}

The unfavourable increase in global warming and the rising planetary temperature are partially caused by the production of construction constituents, which accounts for up to $47 \%$ of carbon emissions [1]. Crucial depletion of forests prerequisites for construction of nonwooden constituents to meet the vast demand for engineering materials is acting as a further impediment to carbon emission reduction [2]. In the spirit of sustainability intertwined with a sense of urgency, construction engineering is progressively headed towards utilising sustainable resources through raw materials direct application in building, to reduce waste and pollution caused by the conventional construction constituents' production $[3,4]$. An emerging research trend that has caught considerable attention is the usage of bamboo as a sustainable substitute to conventional construction material [5]. This research fame can be ultimately attributed to the bamboo's high tensile strength, lightweight, flexibility, and appealing aesthetics and most importantly the fast-growing mechanism which automatically categorises it as a desirable renewable source [6]. The resources of the bamboo in all 
species and types are quite common and rich around the globe with widespread plantation grounds globally. Though, the presence is predominant in the Far East, where 65\% of the species exist and thrive. This gives Asian nations a peculiar opportunity to further develop the construction sector through sustainable usage of the bamboo present abundantly [7]. To pin a constructively comparative argument against bamboo and to highlight bamboo sustainable superiority, timber can be utilised as a comparison counterpart due to their similar utilisation purposes in building and construction. To begin with, the growing phase of bamboo species is considerably shorter than timber; normally, bamboo species might be harvested within 4 to 6 years [8]. It is anticipated that the bamboo can yield up to $50 \mathrm{~m}^{3}$ per hectare/year, whereas timber can produce 2.3 to $10 \mathrm{~m}^{3} /$ year [9]. The mechanical properties of the bamboo species are deemed to be equivalent to the timber and far superior to soft wood in terms of tensile, flexural, and compressive strengths. Though, bamboo species lucratively consumes less energy than conventional construction materials like cement, steel, and concrete [10-12]. Hence, bamboo species are gaining considerable attention in the infrastructure construction and numerous other applications due to favourable biological composition, environmental adaptability in certain applications, and most importantly ecofriendly characteristics [13-15].

Bamboo is a natural resource with significant mechanical properties. This lucrative attribute was likely due to the "cellulose," a main component of bamboo. It was also discovered that bamboo behaved well in buckling due to the maximum energy absorption at the joints. As a result, the failure rate of bamboo in seismic zones is very low $[16,17]$. The effect of humidity on the mechanical characteristic of bamboo specimens has been examined at the macroscopic and cellular stages $[18,19]$. Research showed that humidity could lead to a greater level of ductility [20] whereas the compressive strength and longitudinal shear were extensively decreased [21].

However, the bamboo species has several technical challenges such as geometric and mechanical inconsistency along the longitudinal section [22, 23]. The bamboo was facing natural resistance deterioration in less than 24 months [24], and it was normally decaying in about 4 years if applied outdoor without any treatment $[25,26]$. Furthermore, the bamboo species tend to show sideways grain splitting owing to lopsided shrinkage throughout natural seasoning [27].

An all-in-one study that compressively combines the structural characteristics and microstructural investigation of the bamboo specimen has been scarcely attempted. Hence, to solve existing drawbacks in modern bamboo structural engineering research, an efficient and comprehensive base experimental study on the structural characteristics of the bamboo specimens and the microstructural investigation into the failure mechanism could be lucratively presented for a better and general overview understanding of the performance of the bamboo species fibres, to ultimately lead further expansion of this futuristic research field in construction and materials sustainability.

\section{Materials and Methods}

2.1. Specimen Selection. Dendrocalamus asper was the bamboo species investigated. It is an extremely tough plant indigenous to Southeast Asia that grows as tall canes with long straight portions reaching 65 to 100 feet in height and a diameter of 3 to 8 inches.

It is also commonly termed as betung or giant bamboo. It is a massive, densely clumping tropical and subtropical plant. The bamboo culm is composed of timber and is used to build massive structures such as bridges and houses in local regions where it is present. Laminated boards, furniture, musical instruments, chopsticks, household objects, and handicrafts are all made from this bamboo. Young shoots are sweet and edible and are frequently eaten as a vegetable and used in local [28].

2.2. Specimen Preparation. The bamboo culms were cut into suitable size portions prior to testing, according to the tests mentioned in Table 1.

2.3. Testing. Multilateral testing approaches were carried out on the specified bamboo specimens to adhere to the goals of this research. The mechanical, or physical, characteristics of the specimen were evaluated, and a deep dive into the role of the microstructure on these evaluations was carried out to appropriately assess bamboo specimen suitability as a sustainable construction alternative. This all-in-one inclusive mechanical and microstructural testing and analyses will serve as the base for future bamboo studies and research in the constructional realm.

2.3.1. Microstructural Study. The microstructural analysis of the specimens was conducted through the utilisation of a simplistic handheld mobile microscope and a more sophisticated Field Emission Scanning Electron Microscope (FESEM). The handheld microscope comprised a $5 \mathrm{M}$ pixel image sensor and a high-quality microscopic lens with 3inch thin-film-transistor (TFT) panel. The maximum magnification of the microscope is 500X. It was employed to assess the fracture of the bamboo species on a microscopic level.

Further topography investigation was done through FESEM analysis. It was operated to visualise topographic bamboo surface details at a nanoscale level by shooting electrons from a field emission source and accelerating them in a high electrical field gradient. Hence, the FESEM imaging was adopted in order to study the fibre arrangement and orientation and the critical failure mode of the bamboo species. Meanwhile, Energy Dispersive X-Ray Spectroscopy (EDX) has been executed as well to study the constituent element of the bamboo species.

2.3.2. Direct Tensile Test. The direct tensile test was conducted using the Shimadzu UH-50A tensile testing machine, which is capable of exerting a maximum load capacity of $270 \mathrm{kN}$. The test was carried out in accordance with ASTM 
TABle 1: Dimension of prepared specimens for each test.

\begin{tabular}{lcc}
\hline Type of test & Dimension & Testing standard \\
\hline Direct tensile (end strip test) & $250 \mathrm{~mm}$ long, 15 mm width & ASTM D143-94 \\
Compression & $250 \mathrm{~mm}$ long & BS EN 12390 \\
Elastic modulus & $250 \mathrm{~mm} \mathrm{long}$ & ASTM C469-10 \\
Splitting tensile & $250 \mathrm{~mm}$ long & ASTM C496/C496M-11 \\
Flexural & $500 \mathrm{~mm} \mathrm{long}$ & ASTM C78-10 \\
\hline
\end{tabular}

D143-94 [29]. The test was operated under controlled displacement with a pacing rate of $10 \mathrm{~mm} / \mathrm{min}$. The direct tensile strength of the specimens was computed by the direct application of

$$
\boldsymbol{\sigma}=\frac{\mathbf{F}}{\mathbf{w} \times \mathbf{t}}
$$

where $\mathbf{F}$ is the tensile load at failure $(\mathrm{kN}), \mathbf{w}$ is the width of bamboo specimen $(\mathrm{mm})$, and $t$ is the thickness of bamboo specimen strip (mm).

2.3.3. Compression Test. The compression test was performed using ADR-Auto V2.0 3000 compression machine with a maximum load capacity of $3000 \mathrm{kN}$. The test was carried out in accordance with BS EN 12390 [30].

The hollow cylindrical bamboo specimens were compressively tested parallel to the grain boundaries along the longitudinal direction, with a controlled load pace rate of nearly $3.0 \mathrm{kN} / \mathrm{s}$ until specimen failure.

2.3.4. Elastic Modulus Test. The elastic modulus ratio can be attained through a compression test using the Universal Instron-600 testing machine. The experiments were executed in accordance with ASTM C469-10 [31] under a modified pace rate. The modified test was processed under a displacement-controlled pacing rate of $0.5 \mathrm{~mm} / \mathrm{min}$. The practical elastic modulus value was computed through methodically plotting the stress-strain graph relationship.

2.3.5. Splitting Tensile Test. The splitting tensile test of the specimens was computed in accordance with the ASTM C496/C496M-11 [32] under a modified pace rate. The Universal Instron-600 machine was utilised as a displacement-controlled test apparatus. The pacing rate was revised and fixed to $0.1 \mathrm{~mm} / \mathrm{min}$ until the failure of the specimens. The maximum load that can be withstood by the specimens was captured, and the splitting tensile strength was evaluated through

$$
\sigma=\frac{2 \times \mathbf{F}}{\pi \times D_{1} \times L^{\prime}},
$$

where $\mathbf{F}$ is the compressive load at failure, $\mathbf{D}_{1}$ is the outer diameter of bamboo specimen, and $\mathbf{L}$ is the length of specimen.

2.3.6. Flexural Strength Test. The flexural strength test of the specimens is a destructive test in nature, and it is implemented to determine the flexibility of the targeted material. The tests were conducted in accordance with ASTM C78-10 [33]. The specimen's length was $500 \mathrm{~mm}$, which was tested with a loading rate of $0.067 \mathrm{kN} / \mathrm{s}$. The span length from the support to loading point was $100 \mathrm{~mm}$. The flexural strength of the specimen was assessed using

$$
\boldsymbol{\sigma}=\frac{32 \mathbf{x F x} \mathbf{L D}_{1}}{3 \mathbf{x} \pi \mathbf{x}\left(\mathbf{D}_{1}^{4}-\mathbf{D}_{2}^{4}\right)},
$$

where $\mathbf{F}$ is the load at fracture point, $\mathbf{L}$ is the length between the supports, $\mathbf{D}_{1}$ is the outer diameter, and $\mathbf{D}_{2}$ is the inner diameter of the bamboo specimen.

2.3.7. Nanoindentation Test. Nanoindentation was created to evaluate the mechanical characteristics at extremely small sizes; however, its application to highly heterogeneous materials has offered much fresh understanding about the morphology of elementary particles, due to indentation analysis methods based on micromechanics that relate mechanical characteristics to microstructure and component properties [34]. The load and indentation depth are continually recorded during a nanoindentation test from loading to unloading. Based on the most widely accepted approach proposed by Oliver and Pharr [35], hardness and elastic modulus can be derived from the pure elastic unloading segment of the load-depth trace. A nanoindenter was used to evaluate the samples' nanomechanical characteristics (Hysitron TI 750L $\mathrm{Ubi}^{\mathrm{TM}}$ ). To acquire their average nanohardness values, load-controlled nanoindentation experiments were performed on each IMC layer of the crosssectioned samples. The maximum load was $2000 \mu \mathrm{N}$, and the loading rate used was $200 \mu \mathrm{N} / \mathrm{s}$.

Equation (4) can visualise how reduced elastic modulus $\mathbf{E}_{\mathbf{r}}$ can be calculated theoretically. Equations (5) and (6) can then be used to compute the MOE and hardness of materials:

$$
\begin{aligned}
\mathbf{E}_{\mathbf{r}} & =\frac{\sqrt{\pi}}{2} \frac{\mathbf{s}}{\mathbf{A}_{\mathbf{C}}}, \\
\frac{1}{\mathbf{E}_{\mathbf{r}}} & =\frac{1-\mathbf{v}^{2}}{\mathbf{E}}+\frac{1-\mathbf{v}_{\mathbf{i}}^{2}}{\mathbf{E}_{\mathbf{i}}}, \\
\mathbf{H} & =\frac{\mathbf{P}}{\mathbf{A}_{\mathbf{C}}},
\end{aligned}
$$

where $\mathbf{E}_{\mathbf{i}}$ and $\mathbf{v}_{\mathbf{i}}$ are the elastic modulus and Poisson ratio of the tips, respectively. $\mathbf{E}_{\mathbf{i}}$ is $1141 \mathrm{GPa}$ for diamond tips, while $\mathbf{v}_{\mathbf{i}}$ is 0.07 . $\mathbf{E}$ and $\mathbf{v}$ are the elastic modulus and Poisson ratio of samples, respectively. Despite the fact that there is currently 
no experimental data on $\mathbf{v}$ for the cell wall of bamboo or wood fibres, a value of 0.22 was used as the Poisson ratio of bamboo fibres based on a study by Yu et al. [36] that used the probable average of a series of comparative research investigations of materials that have similar properties to bamboo.

\section{Results and Discussion}

3.1. Compositional Analysis (EDX Test). The Energy Dispersive X-Ray Spectroscopy (EDX) has been carried out to determine the constituent components of the bamboo specimen. It was discovered that the specimen comprised carbon as a major constituent from $45.9 \%$ to $77.4 \%$ of the total weightage, followed by the oxygen $(\mathrm{O})$ component from $22.52 \%$ to $49.6 \%$ of the total weightage. Besides, the nitrogen $(\mathrm{N})$ element has also significant constituent percentage from $3.0 \%$ to $13.2 \%$ of the total weightage. Figure 1 exhibits a representative EDX spectrum, showing the constituent components in the bamboo specimen.

3.2. Direct Tensile Strength. One of the outstanding features of the bamboo specimen used as a structural material is that it has prominent direct tensile strength, as compared with the conventional materials used in conventional structures i.e., concrete and steel. For concrete, its tensile strength is only about one-tenth of its compressive strength, in the range of 1.5-9 MPa. However, for the case of bamboo, the tensile strength was recorded as about $226.45 \mathrm{MPa}$, which can be relatively comparable to the tensile strength $(250 \mathrm{MPa})$ of structural steel as stated in ASTM A-36 [37]. The direct tensile failure of the tested bamboo specimens is demonstrated in Figure 2. It can be clearly seen that the plane failure has occurred along the bamboo strips, and the debonding of fibre along the longitudinal direction and fracture across the bamboo strips are depicted in Figure 2. However, there are yet several strong and long fibres that were unbroken under the recorded tensile strength earlier. In another similar report, Paraskeva et al. [38] achieved about $212.85 \mathrm{MPa}$ tensile strength of the bamboo specimen tested.

3.3. Splitting Tensile Strength. Concrete, as a conventional construction material, is deemed an isotropic homogeneous structural material. This means that the direct tensile strength is an indicator of the splitting tensile strength as well. On the other hand, bamboo is rather considered quite the opposite, a nonisotropic homogenous material. Hence, the directional tensile strength between the longitudinal and lateral directions might vary.

The crack propagation of bamboo under splitting loading can be sought out through stress-strain curve. From the stress-strain curve of the bamboo specimen (Figure 3), three typical drops have been observed in the curve. The first drop in the curve represents the crack initiating. Subsequently, the second drop indicates the merging of the microcracks, and the final drop signifies the final merging of the longitudinal cracks, causing the ultimate failure of the specimen and indicating the maximum splitting tensile strength. The splitting tensile strength of the bamboo specimen was found out to be $0.055 \mathrm{MPa}$ through elaborate visualisation of the graph shown in Figure 3. The splitting tensile strength is considerably lower than the direct tensile strength of the specimen. The substantial deviation of the two directional tensile strengths can be pinpointed towards the fibre arrangement of the bamboo specimens. Bamboo fibre naturally runs in longitudinal direction. In the earlier direct tensile strength test, the individual fibres were broken. On the other hand, in the splitting tensile strength test, the fibres were splitting from fibre matrix as shown in the optical microscope image (Figure 4). The final splitting tensile modulus achieved was about $2.88 \mathrm{MPa}$, considerably lower than the direct tensile modulus of about $3.96 \mathrm{GPa}$.

3.4. Tensile Failure Mechanism. Specimen failure under tensile force could be due to crack propagation across the cross-section being more constricted by the resilient strength of the fibres, as a tension failure mode of bamboo needs to undergo two modes of failure under the same plane failure mechanism, i.e., along the longitudinal direction and the transverse direction.

The proposed mechanism of fibre debonding along the longitudinal direction and fracture across the bamboo strips is depicted in Figure 5. It was understood that it was the weaker interfacial bonding between the parenchyma cells that allowed the propagation of the cracks. When the cracks were encountered by the lengthy strong bundles of fibre, then the propagation diverged almost $90^{\circ}$ along the fibres as illustrated in Figure 5. The fibre was very strong under tensile forces, and the cracks were unlikely to cut it crossways. It is uncommon for the fibres to break unless extremely high energy is introduced. The FESEM micrograph of bamboo specimens failed under tension (Figure 6), further confirming that fibre debonding or pull-out was more likely to occur, specifically at the inner weaker zone due to low density of fibres.

3.5. Compressive Strength. The maximum compressive strength of the bamboo specimens at a room moisture content at room conditions was $44.3 \mathrm{MPa}$ according to the experimental compressive stress-strain graph shown in Figure 7. The compressive stress increases almost linearly until it reached the specimen's maximum ultimate compressive stress, after which it progressively decreased, indicating the specimen's compressive failure. It can be said that it is on par with the compressive strength of a standard constructional concrete material. The compressive failure modes of the specimens are exhibited in Figure 8. The microscopic view of the compressive failure mode has revealed fibre detachment near the surface of the culm. Further investigation showed two types of failure modes occurring during the compression test of the specimens, i.e., splitting and end bearing failure. The splitting failure appeared due to the distinctive splitting cracks initiated along the specimen's culms. This phenomenon might be due to the low moisture content, which was $11.1 \%$ at room temperature. It is usually the moisture content 


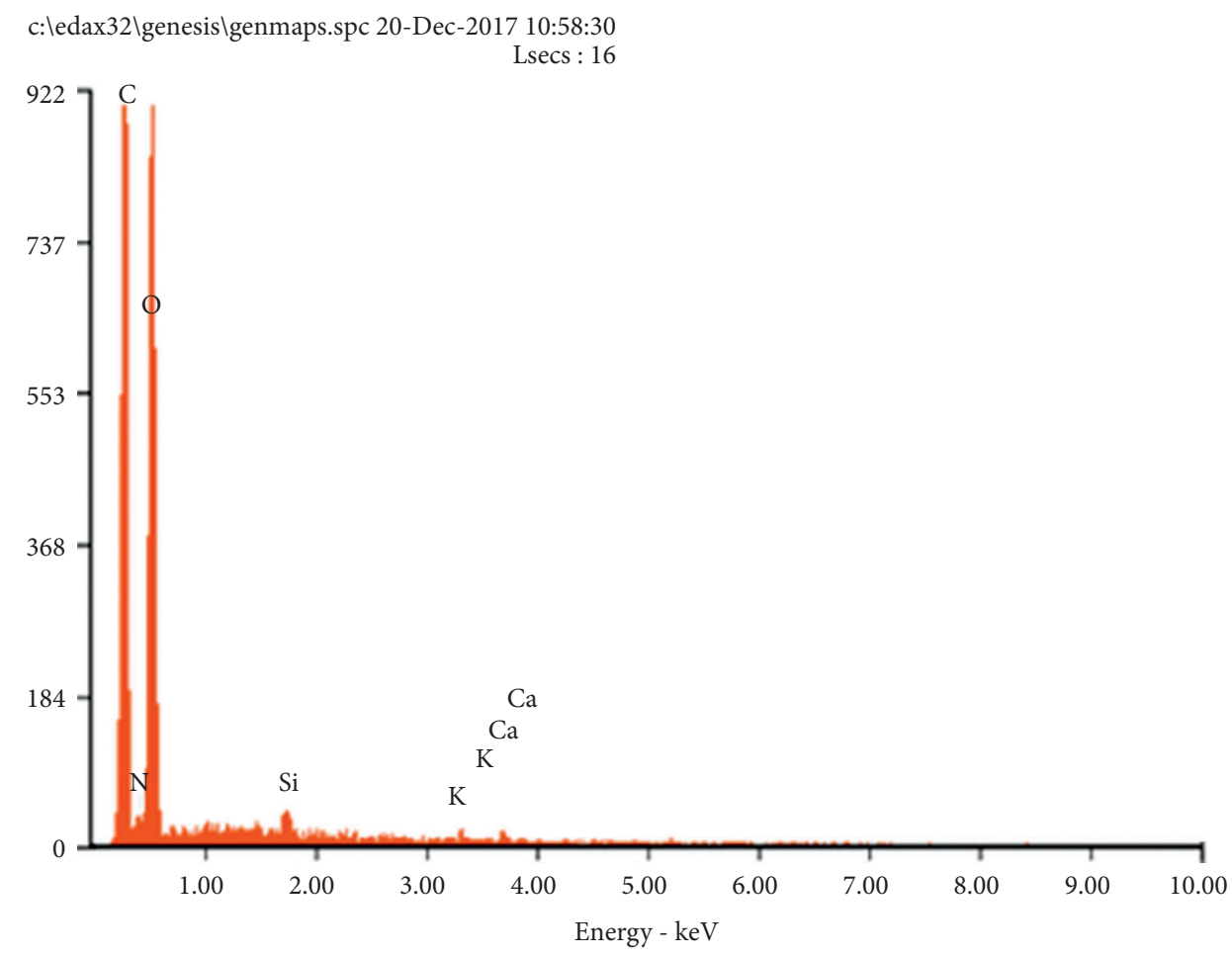

FIGURE 1: EDX spectrum of the bamboo specimen.

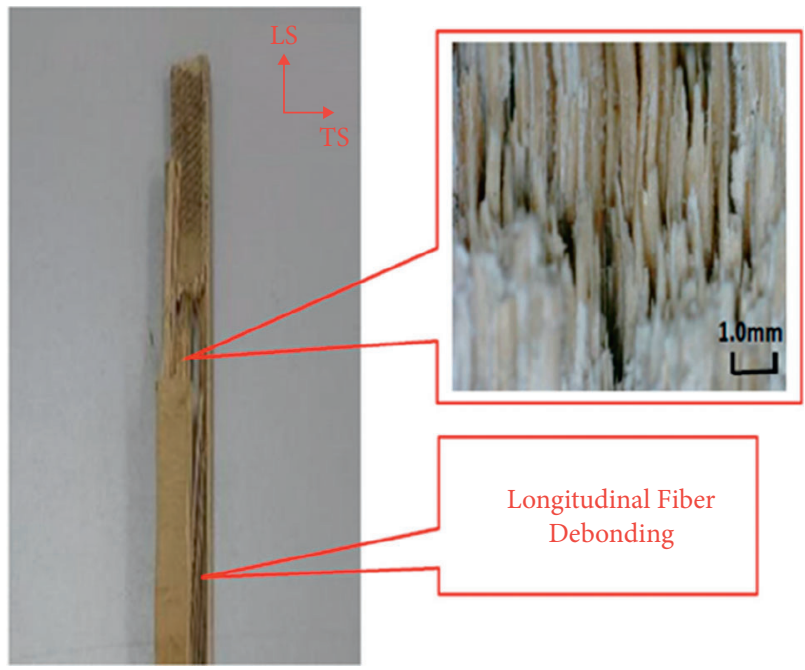

Figure 2: Optical microscope image of the failed direct tensile tested specimens.

of the specimen that determines the type of compressive failure at hand. With high moisture content, specimens showed a failure in the end bearing. On the other hand, specimens with low moisture content showed a failure in fibre splitting [39].

3.6. Compression Test Failure Mechanism. The compression failure of bamboo specimens was essential to identify individual plane failure mechanism, which was along the longitudinal direction of the specimen's culm. This mechanism was caused by the splitting behaviour of the

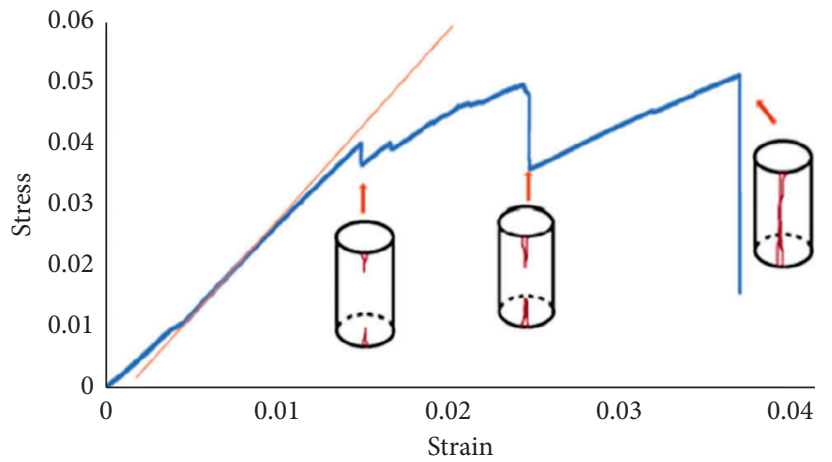

FIGURE 3: Splitting tensile stress vs. strain curve.

specimens in the compression test as demonstrated in Figure 8. Furthermore, it was also shown that the plane failure mechanism was initiated either along the bamboo fibres debonding or along the parenchyma cells as shown in Figures 9(a) and 9(b).

Through the FESEM microscopic view of the longitudinal cross-section of the bamboo specimen, it was notably seen that the specimen constitutes some sponge-like structure as shown in the highlighted area in Figure 10(a). The sponge-like structures of the parenchyma cells project weaker spots in the topography shown, and according to previous tests, the parenchyma cells can be labelled as a noncontributor to the strength of the specimen. However, Schott [40] showed that these cells might serve as some sort of shock absorbers and contribute to the stiffness against bending. It was clarified that when the axial compression was enduring on the specimen, the fibre was robust enough to 


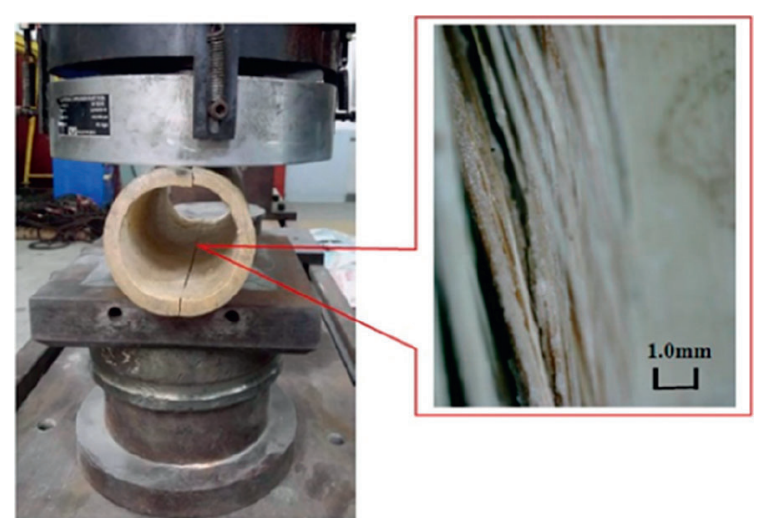

FIgURE 4: Optical microscope image of the failed tensile splitting specimen.

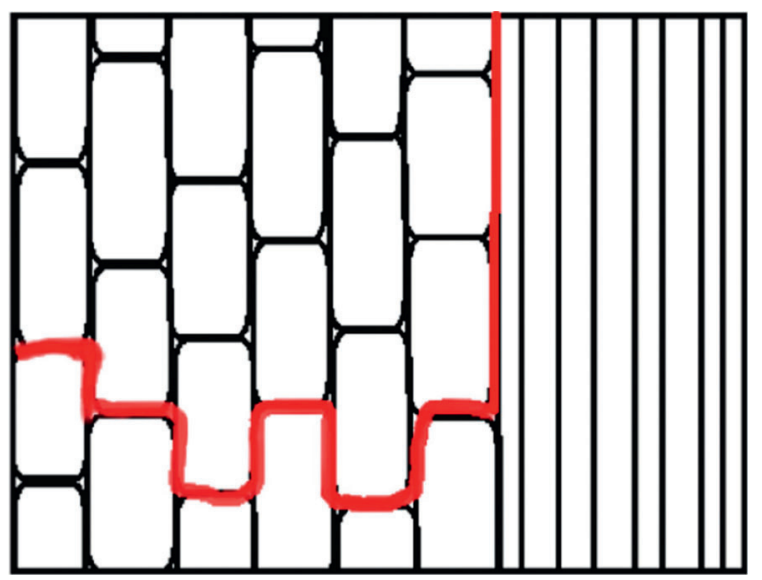

FIGURE 5: Schematic diagram showing the proposed crack propagation path in the bamboo tensile test.

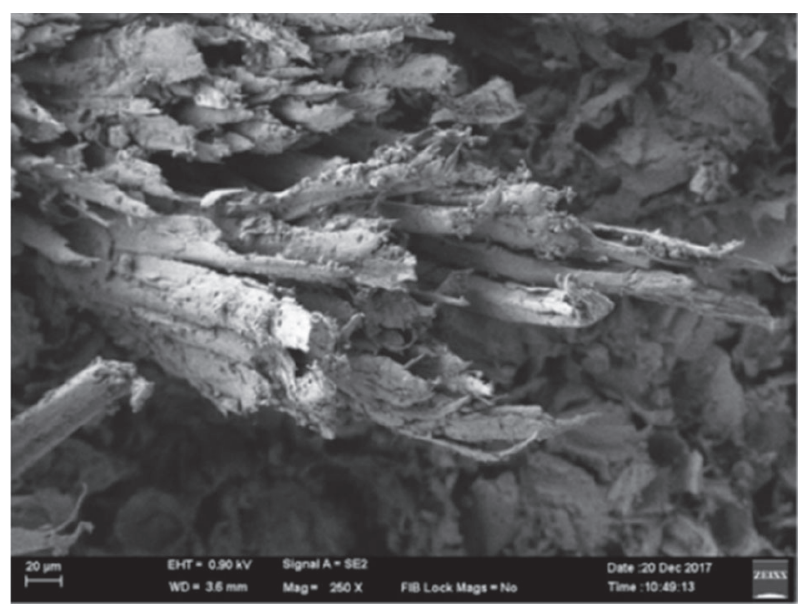

FIgURE 6: Bamboo fibre pull-out behaviour under FESEM inspection.

resist the stress with the help of the spongy parenchyma cells that were able to deform. Hence, the longitudinal weaker plane was likely to be developed, causing the bamboo culm to split. The tensile force was unlikely to be involved in the

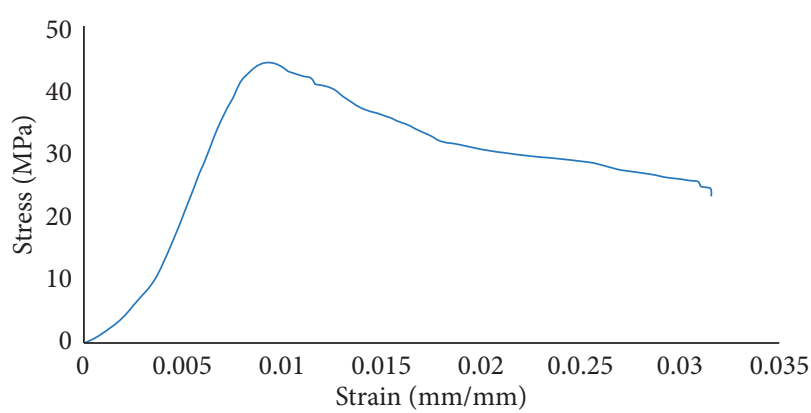

FIgURE 7: Compressive stress-strain curve of the specimen.

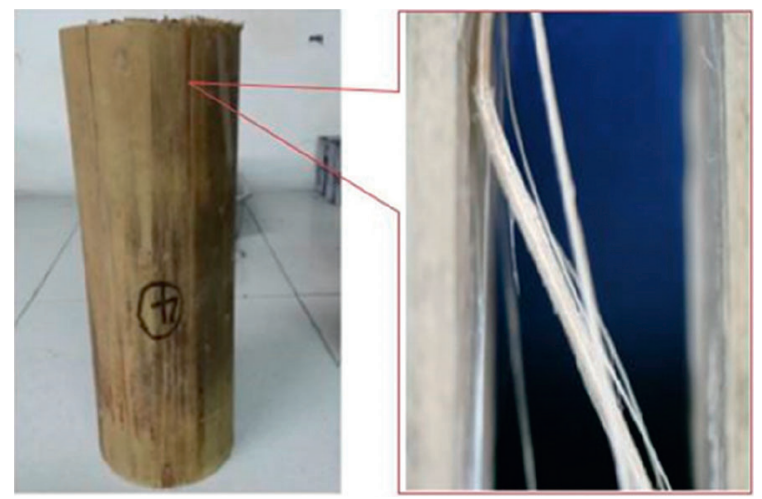

FIgURE 8: Final resultant image of the compression test and a microscopic view of the compressed sample.

pull-out behaviour of the fibre as well as cracks across the section. Since the interfacial bonding in between the cells or fibres was weaker, lower energy was required for debonding causing the failure of the specimen. The spongy cells were composed of tiny holes which ranged from 0.8 to $2.0 \mu \mathrm{m}$ as revealed in Figure 10(b). This might further reduce the surface bonding area and increase the ease of failure plane mechanism, leading to medium strength of the specimen in the context of compression, which showed that either fibre debonding or plane fracture mechanism would usually occur due to the compression failure of the specimen.

3.7. Elastic Modulus. The elastic modulus precisely represents the stiffness of the material. In this case, the elastic modulus value was deduced from the compressive stressstrain curve (Figure 9), being about 7.98 GPa. It was slightly higher than that of the Phyllostachys pubescens specimens $(7.80 \mathrm{GPa})$ but lower than that of the Bambusa pervariabilis specimens (9.30 GPa) [41]. Comparatively discussing the bamboo specimen with concrete in terms of elastic modulus, we consider the former to be of a low elastic modulus level as the average elastic modulus for concrete is more than $20 \mathrm{GPa}$ [41].

3.8. Flexural Strength. The ultimate attained flexural strength of the bamboo specimens was $9.42 \mathrm{MPa}$, as the specimen reached the maximum flexural recorded experimental load of $2.72 \mathrm{kN}$. The method employed in this 


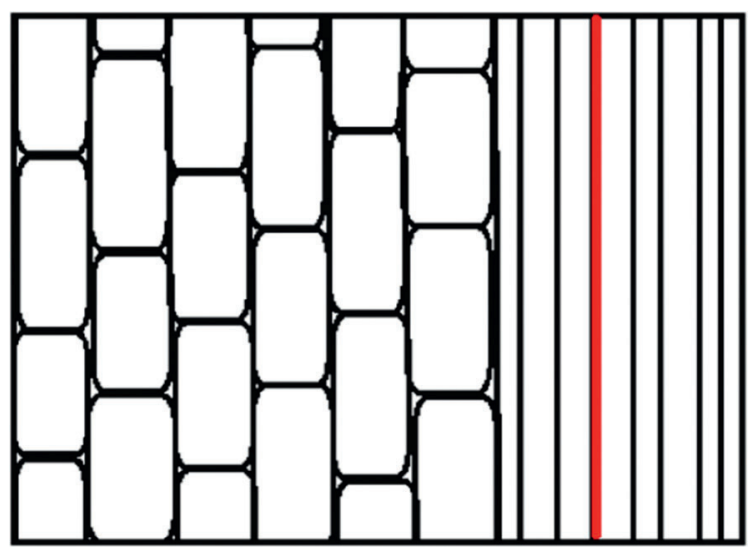

(a)

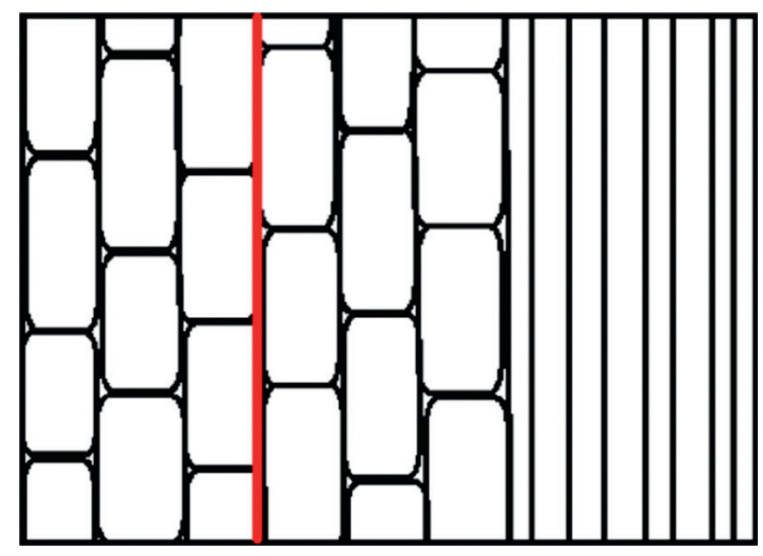

(b)

FIGURE 9: (a) Fibre debonding in compression test. (b) Plane fracture along parenchyma cell in compression test.

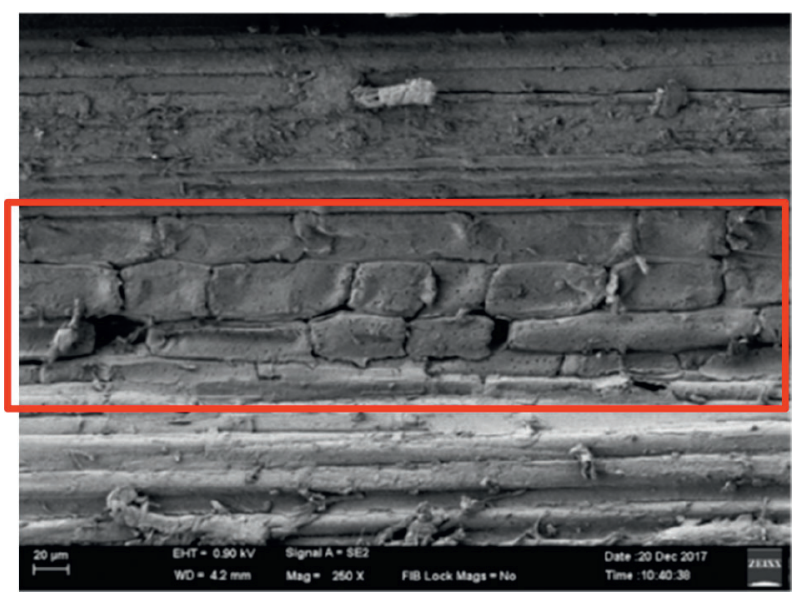

(a)

Figure 10: (a) Spongy structure in bamboo.

experiment was modified based on the concrete prism bending test, and the specimen length was not enough for the usual bending test. Hence, the splitting failure mode was observed due to the specimens split into two halves as shown in Figure 11(a). Observations throughout the test duration show that the cracks initiated at the side of the upper and lower half and propagated along the same direction as the fibres. FESEM characterisations of the failed flexural specimen further justified the fact that fibre debonding takes place along the direction of crack propagation (Figure 11(b)).

3.9. Flexural Test Failure Mechanism. From the microstructural investigation, it was found that the failure of the specimens in the flexural test was mainly attributed to the splitting behaviour amongst the fibres, because of the weakness of the fibre matrix that has an adhesive effect amongst the fibres.

Fibre breaking was not the real cause of the failure of the specimen, but rather the length of the specimen was not

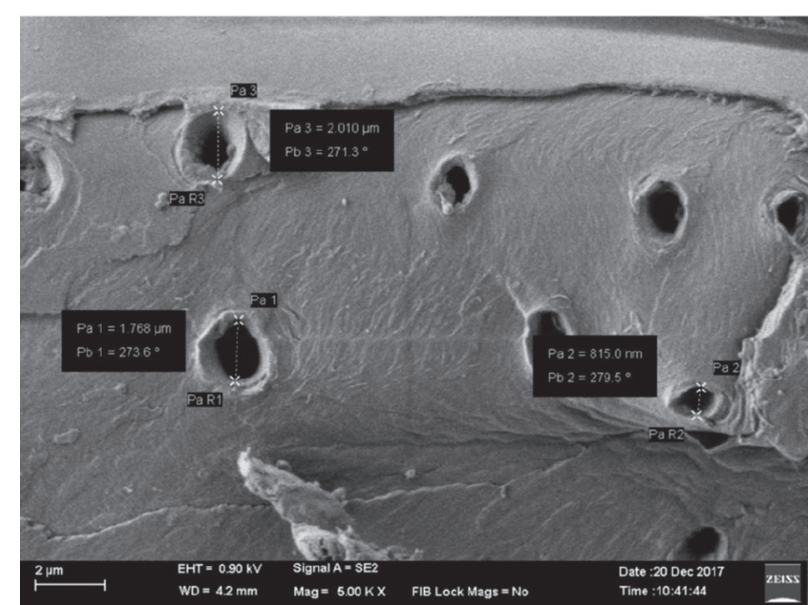

(b)

(b) Closer view of spongy structure in bamboo.

adequate enough in the modified flexural test, which might not have been caused by the critical bending. Therefore, the flexural strength of the specimen was significantly lower than the tensile strength.

However, it was found out that when the fibre was being torn off from the other fibres, the outermost layer of the fibre was unable to endure the extreme pressure and caused fibres breakage as shown in Figure 11. The single layer of fibre was made of many layers of microfibrils which were arranged in different fibrillar orientations as known from the investigation of the specimen. This polylamellate structure does not exist in the cell walls of fibres or tracheid of normal wood.

3.10. Nanoindentation. A diamond nanoindenter tip was utilised to scan and locate a bamboo fibre cell wall in this study, and then the indenter tip was placed on the cell wall in situ to conduct nanoindentation testing. On the cross-sectional of bamboo fibres, a series of nanoindentation tests with varying indentation loads were made. Figure 12 shows the intended nanoindentation location of the fibre cell wall 

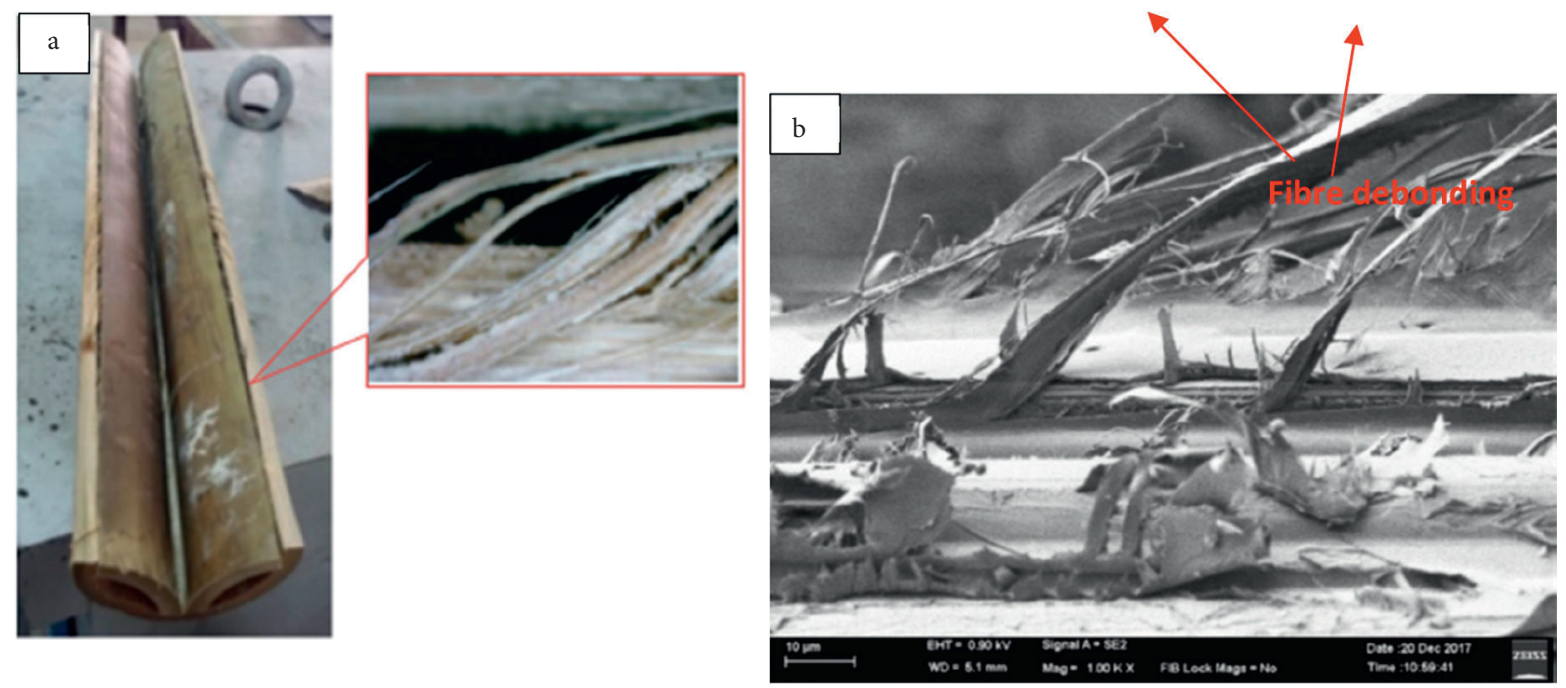

Figure 11: (a) Optical microscope images and (b) FESEM micrograph of the failed flexural test specimen.

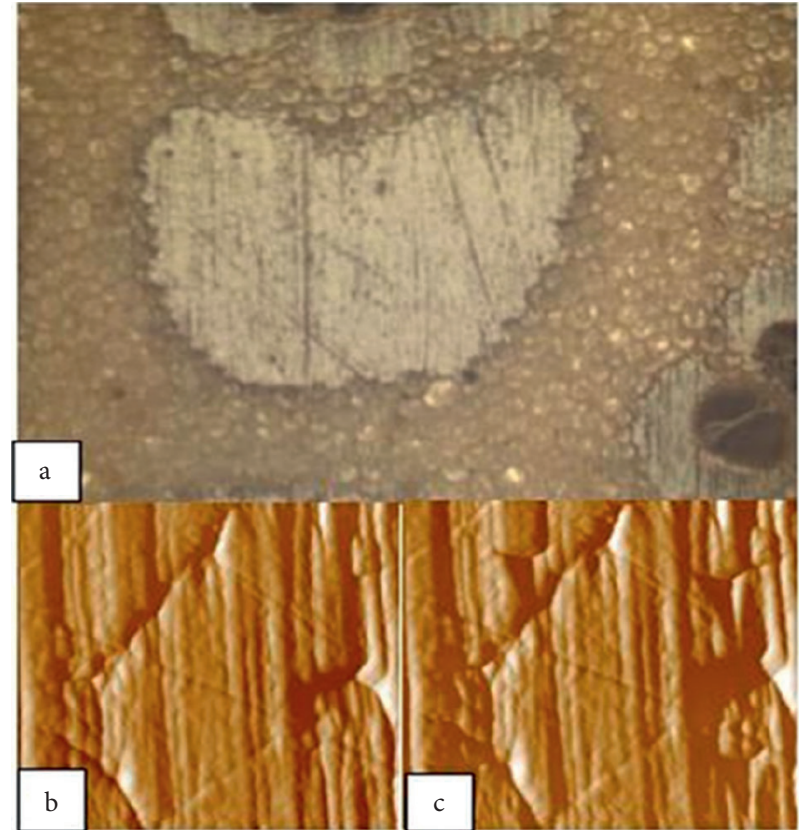

Figure 12: Fibre cell wall from (a) microscopic level, (b) AFM before indentation, and (c) AFM after indentation.

and the AFM image of the after-indentation effect on a microscopic level. The hardness and elastic modulus of nanoindentation reported here are the average of several nanograins tested. There were no fissures at the corners of these indents, and this indicates that the nanograin formations in the specimens are well bonded. It can be inferred that the bamboo fibre cell wall is a ductile material. The cell wall's nanoindentation hardness and elastic modulus were found to be $0.35 \pm 0.08 \mathrm{GPa}$ and $16.08 \pm 2.00 \mathrm{GPa}$, respectively. These results are considerably consistent with those reported by other researchers [36].

Nanoindentation studies were also performed on the parenchyma cell wall of the bamboo specimen as shown in Figure 13. The hardness and elastic modulus values of

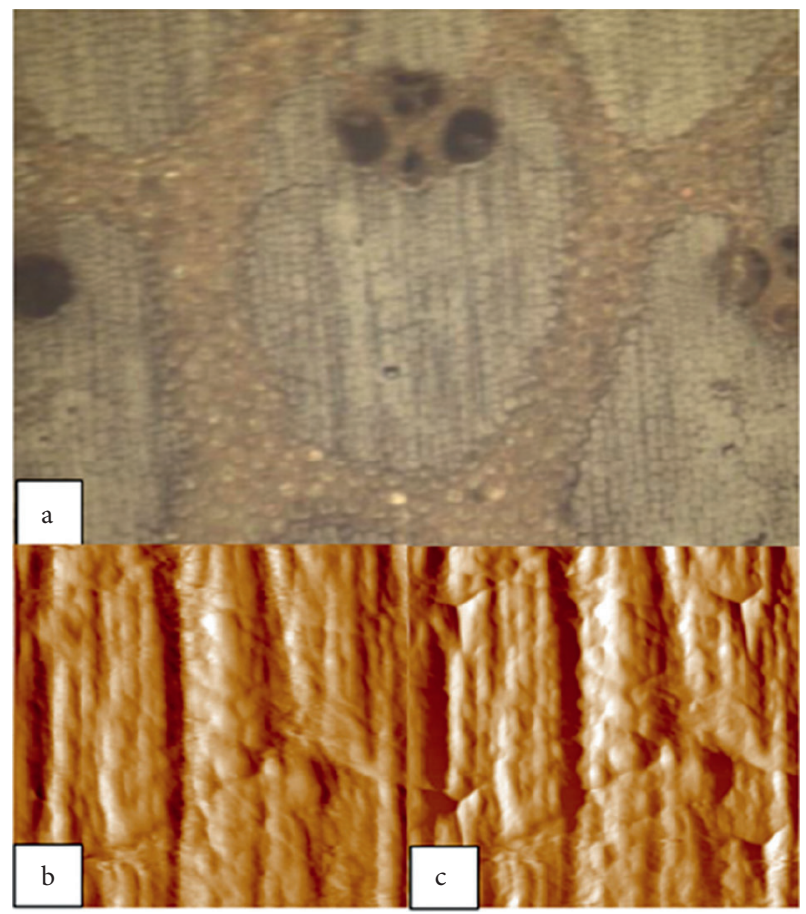

FIGURE 13: Parenchyma cell wall from (a) microscopic level, (b) AFM before indentation, and (c) AFM after indentation.

bamboo fibre cell walls and parenchyma cell walls are tabulated in Table 2. The elastic modulus of the fibre cell walls is three times that of the parenchyma cell walls, yet the hardness values are comparable. Fibres act as reinforcements for matrix-parenchyma cells in bamboo. Bamboo fibres contribute mostly to the stiffness (toughness) of bamboo culms, according to the rule of combination for composite materials. The results of the nanoindentation correlate with previous compression test failure mechanism results discussed in Section 3.6, which confirms that crack propagation takes place prevalently along the parenchyma cells, instead of the cell walls. 
TABLE 2: Hardness and elastic modulus results of nanoindentation testing.

\begin{tabular}{lcc}
\hline Bamboo component & Hardness $(\mathrm{GPa})$ & Elastic modulus $(\mathrm{GPa})$ \\
\hline Fibre cell wall & $0.35 \pm 0.08$ & $16.08 \pm 2.0$ \\
Parenchyma cell wall & $0.21 \pm 0.09$ & $3.17 \pm 0.66$ \\
\hline
\end{tabular}

\section{Conclusions}

The aim of this research was to examine the structural and microstructural characteristics of the Dendrocalamus asper bamboo. As a result of this investigation, the significant novel findings of the structural and microstructural characteristics of bamboo specimens are as follows:

(i) Dendrocalamus asper bamboo can be a good constructional material as it possesses excellent structural properties such as tension strength of $226.45 \mathrm{MPa}$ and compressive strength of $44.3 \mathrm{MPa}$. The direct tensile strength of bamboo was reported to be comparable to mild steel.

(ii) The modulus of elasticity under the compression and tension was about $7.98 \mathrm{GPa}$ and $3.96 \mathrm{GPa}$, respectively.

(iii) In tensile testing, Dendrocalamus asper bamboo showed plane failure as tensile failure mechanism due to the strong fibre and parenchyma cells which contributed to the fracture toughness.

(iv) The tensile strength of the bamboo was remarkably high as energy consumption was needed for two modes of failure under the same plane failure mechanism to occur, i.e., along the longitudinal direction and the transverse direction.

(v) The compressive strength of bamboo was $44.3 \mathrm{MPa}$, which correlates to a medium-to-high compressive strength comparable to that of conventional construction materials, as energy consumption was only needed for one mode of failure, i.e., along the longitudinal direction.

(vi) The critical failure path of bamboo was along the interface of the parenchyma cells or fibres during compressive strength testing.

(vii) Bamboo fibres with nanograin structures are ductile in nature. The cell wall's nanoindentation hardness and elastic modulus were found to be $0.35 \pm 0.08 \mathrm{GPa}$ and $16.08 \pm 2.0 \mathrm{GPa}$, respectively.

\section{Data Availability}

The data can be made available on request through the corresponding authors.

\section{Conflicts of Interest}

The authors declare that they have no conflicts of interest.

\section{Acknowledgments}

This project was supported by the Deanship of Scientific Research at Prince Sattam Bin Abdulaziz University under the research project number 16794/01/2020 and Universiti Malaya Faculty Research Grant (GPF) 2019 under the project GPF008A-2019 (Development of Green and SpaceEfficient Low-Cost Structures from Renewable Materials).

\section{References}

[1] D. Yang, H. Li, Z. Xiong et al., "Mechanical properties of laminated bamboo under off-axis compression," Composites Part A: Applied Science and Manufacturing, vol. 138, Article ID 106042, 2020.

[2] J. Xie, J. Qi, T. Hu, C. F. De Hoop, C. Y. Hse, and T. F. Shupe, "Effect of fabricated density and bamboo species on physicalmechanical properties of bamboo fiber bundle reinforced composites," Journal of Materials Science, vol. 51, no. 16, pp. 7480-7490, 2016.

[3] L. Molari, L. Mentrasti, and M. Fabiani, "Mechanical characterization of five species of Italian bamboo," Structures, Elsevier, vol. 24, , pp. 59-72, 2020.

[4] M. Ramesh, C. Deepa, and A. Ravanan, "Bamboo fiber reinforced concrete composites," in Bamboo Fiber Composites. Composites Science and Technology, M. Jawaid, S. Mavinkere Rangappa, and S. Siengchin, Eds., Springer, Berlin, Germany, 2021.

[5] P. Van Der Lugt, A. A. J. F. v. d. Dobbelsteen, and J. Janssen, "An environmental, economic and practical assessment of bamboo as a building material for supporting structures," Construction and Building Materials, vol. 20, no. 9, pp. 648-656, 2006.

[6] M. Gutierrez and C. Maluk, "Mechanical behaviour of bamboo at elevated temperatures - experimental studies," Engineering Structures, vol. 220, Article ID 110997, 2020.

[7] H. P. S. Abdul Khalil, I. U. H. Bhat, M. Jawaid, A. Zaidon, D. Hermawan, and Y. S. Hadi, "Bamboo fibre reinforced biocomposites: a review," Materials \& Design, vol. 42, pp. 353-368, 2012.

[8] J. Vogtländer, P. Van Der Lugt, and H. Brezet, "The sustainability of bamboo products for local and Western European applications. LCAs and land-use," Journal of Cleaner Production, vol. 18, pp. 1260-1269, 2010.

[9] K. D. Flander and R. Rovers, "One laminated bamboo-frame house per hectare per year," Construction and Building Materials, vol. 23, no. 1, pp. 210-218, 2009.

[10] M. Kamruzzaman, S. Saha, A. Bose, and M. Islam, "Effects of age and height on physical and mechanical properties of bamboo," Journal of Tropical Forest Science, vol. 20, pp. 211-217, 2008

[11] D. Ren, Z. Yu, W. Li, H. Wang, and Y. Yu, "The effect of ages on the tensile mechanical properties of elementary fibers extracted from two sympodial bamboo species," Industrial Crops and Products, vol. 62, pp. 94-99, 2014.

[12] Y. Xiao, L.-Y. She, B. Shan, Q. Zhou, G. Chen, and R.-Z. Yang, "Application of modern bamboo struture to reconstruction after Wenchuan earthquake," Journal of Natural Disasters, vol. 18, pp. 14-18, 2009.

[13] J. M. O. Scurlock, D. C. Dayton, and B. Hames, "Bamboo: an overlooked biomass resource?" Biomass and Bioenergy, vol. 19, no. 4, pp. 229-244, 2000.

[14] Y. Sheng, B. Zhang, Y. Yan, H. Li, Z. Chen, and H. Chen, "Laboratory investigation on the use of bamboo fiber in asphalt mixtures for enhanced performance," Arabian Journal 
for Science and Engineering, vol. 44, no. 5, pp. 4629-4638, 2019.

[15] M. Ramesh, L. RajeshKumar, and V. Bhuvaneshwari, "Bamboo fiber reinforced composites," in Bamboo Fiber Composites. Composites Science and Technology, M. Jawaid, S. Mavinkere Rangappa, and S. Siengchin, Eds., Springer, Berlin, Germany, 2021.

[16] P. G. Dixon and L. J. Gibson, "The structure and mechanics of Moso bamboo material," Journal of the Royal Society Interface, vol. 11, no. 99, Article ID 20140321, 2014.

[17] W. Liese and M. Köhl, Bamboo-The Plant and its Uses, Springer, Berlin, Germany, 2015.

[18] T. Y. Lo, H. Z. Cui, and H. C. Leung, "The effect of fiber density on strength capacity of bamboo," Materials Letters, vol. 58, no. 21, pp. 2595-2598, 2004.

[19] S. Jakovljević, D. Lisjak, Ž. Alar, and F. Penava, "The influence of humidity on mechanical properties of bamboo for bicycles," Construction and Building Materials, vol. 150, pp. 35-48, 2017.

[20] S. Amada and S. Untao, "Fracture properties of bamboo," Composites Part B: Engineering, vol. 32, no. 5, pp. 451-459, 2001.

[21] J. Song, J. Utama Surjadi, D. Hu, and Y. Lu, "Fatigue characterization of structural bamboo materials under flexural bending," International Journal of Fatigue, vol. 100, pp. 126-135, 2017.

[22] R. Lorenzo, M. Godina, L. Mimendi, and H. Li, "Determination of the physical and mechanical properties of moso, guadua and oldhamii bamboo assisted by robotic fabrication," Journal of Wood Science, vol. 66, pp. 1-11, 2020.

[23] R. Lorenzo, L. Mimendi, M. Godina, and H. Li, "Digital analysis of the geometric variability of Guadua, Moso and Oldhamii bamboo," Construction and Building Materials, vol. 236, Article ID 117535, 2020.

[24] B. C. Chen, M. Zou, G. M. Liu, J. F. Song, and H. X. Wang, "Experimental study on energy absorption of bionic tubes inspired by bamboo structures under axial crushing," International Journal of Impact Engineering, vol. 115, pp. 48-57, 2018.

[25] J. Rao, J. Jiang, N. K. Prosper et al., "Combination of polyethylene glycol impregnation and paraffin heat treatment to protect round bamboo from cracking," Royal Society Open Science, vol. 6, no. 11, Article ID 190105, 2019.

[26] F. Sun, N. Prosper, H. Wu et al., "A review on the development of wood and bamboo preservation," Journal of Forestry Engineering, vol. 2, pp. 1-8, 2017.

[27] K.-T. Wu, "The effect of high-temperature drying on the antisplitting properties of makino bamboo culm (Phyllostachys makinoi Hay.)," Wood Science and Technology, vol. 26, pp. 271-277, 1992.

[28] P. Malanit, M. C. Barbu, and A. Frühwald, "Physical and mechanical properties of oriented strand lumber made from an Asian bamboo (Dendrocalamus asper Backer)," European Journal of Wood and Wood Products, vol. 69, no. 1, pp. 27-36, 2011.

[29] D. Astm, Standard Test Methods for Small Clear Specimens of Timber, ASTM International, West Conshohocken, PA, USA, 2000.

[30] B. S. En, Testing Hardened Concrete: Compressive Strength of Test Specimens, BSI Standards, London, UK, 2009.

[31] Aci Committee, Standard Test Method for Static Modulus of Elasticity and Poisson's Ratio of Concrete in Compression, ACI Committee, Farmington Hills, MI, USA, 2014.
[32] A. S. T. M. Norma, Standard Test Method for Splitting Tensile Strength of Cylindrical concrete Specimens, pp. 469-490, ASTM International, West Conshohocken, PA, USA, 2004

[33] C. Astm, "Standard test method for flexural strength of concrete (using simple beam with third-point loading)," in American Society For Testing And MaterialsASTM International, West Conshohocken, PA, USA, 2010.

[34] F.-J. Ulm, "Nano-engineering of concrete," Arabian Journal for Science and Engineering, vol. 37, no. 2, pp. 481-488, 2012.

[35] W. C. Oliver and G. M. Pharr, "An improved technique for determining hardness and elastic modulus using load and displacement sensing indentation experiments," Journal of Materials Research, vol. 7, no. 6, pp. 1564-1583, 1992.

[36] Y. Yu, B. Fei, B. Zhang, and X. Yu, "Cell-wall mechanical properties of bamboo investigated by in-situ imaging nanoindentation," Wood and Fiber Science, vol. 39, pp. 527-535, 2007.

[37] Astm A36/A36M-05, Standard Specification for Carbon Structural Steel, ASTM International, West Conshohocken, PA, USA, 2005.

[38] T. S. Paraskeva, G. Grigoropoulos, and E. G. Dimitrakopoulos, "Design and experimental verification of easily constructible bamboo footbridges for rural areas," Engineering Structures, vol. 143, pp. 540-548, 2017.

[39] K. F. Chung and W. K. Yu, "Mechanical properties of structural bamboo for bamboo scaffoldings," Engineering Structures, vol. 24, no. 4, pp. 429-442, 2002.

[40] W. Schott, "Bamboo under the Microscope," Power Fibers Online Magazine, pp. 1-24, Power Fibers \& Talsma Web Creations, Zeeland, MI, USA, 2003, http://www.powerfibers. com/Bamboo_under_the_Microscope.pdf.

[41] H. Y1LD1R1M and O. Sengul, "Modulus of elasticity of substandard and normal concretes," Construction and Building Materials, vol. 25, pp. 1645-1652, 2011. 